\title{
Gold catalyst recycling study in base-free glucose oxidation reaction
}

\author{
C. Megías-Sayago*, L. Bobadilla, S. Ivanova, A. Penkova, M. A. Centeno, J. A.
}

Odriozola

Departamento de Química Inorgánica, Universidad de Sevilla e Instituto de Ciencia de Materiales de Sevilla, US-CSIC, Américo Vespucio 49, 41092, Sevilla, Spain

corresponding autor: cristina.megias@icmse.csic.es

\begin{abstract}
This work is devoted to the study of viability of immobilized gold colloids on carbon as catalysts for the base-free glucose oxidation reaction with a special emphasis made on catalysts' recycling, operational life and possible routes for deactivation/reactivation under batch conditions. The observed catalytic behavior is related to all possible manners of deactivation, like gold metal state changes (particle size agglomeration or leaching), support modifications or active sites blocking by intermediates. In an attempt to recover the initial catalytic activity, the samples are subjected to different treatments such as $\mathrm{H}_{2} \mathrm{O}$ and $\mathrm{NaOH}$ washings and calcination. The failure of the regeneration procedures to recover the initial activity and after detailed catalyst' characterization allows us to find out the main cause of deactivation.
\end{abstract}

Keywords: base-free glucose oxidation, gold, activated carbon, deactivation, recycling 


\section{Introduction}

In the last decades, an increasing necessity of readdressing the interest from fossil raw materials to renewable feedstocks arises due to the continuous depletion of the formers. A reorientation of the scientific interest towards carbohydrates as feedstock for fine chemistry is currently of actuality [1]. The "green catalysis" approach including orientation toward aqueous media low temperature catalytic transformations and carbohydrates highly functionalized type molecules increases by far its potential as fine chemical feedstock $[2,3]$. It is then of crucial importance to explore this potential toward efficient, environmentally friendly and economically viable technologies for large-scale conversion of carbohydrates into industrially viable bulk or intermediate compounds for chemical, pharmaceutical or polymeric use [4]. Among the existing reactions for carbohydrates conversion, the selective oxidation of plant-biomass monomers (hexoses or pentoses) to corresponding carboxylic acids presents a possibility to easy integration in already existing technologies and therefore an important economic interest. The heterogeneously catalyzed transformation of glucose to gluconic acid received important attention [5-8]. Nevertheless, the proposed processes must show an important activity/selectivity balance and especially long term stability in order to be competitive to the existing biotechnological process for gluconic acid production. The slow to severe catalyst deactivation and side reactions products are considered as the main challenges to undertake for future industrialization of heterogeneous process [9].

Among the metal catalysts discussed for selective oxidation of glucose to gluconic acid, the noble metal based ones are the most frequently reported. Important productivity was reported for Pt and Pd based catalysts [10-12]. Especially improved activities and product selectivity of the Pt based catalysts were obtained after doping with Bi [12,13]. However, during the reaction, bismuth leaching was observed which converts this 
catalytic system inadequate for pure chemicals production and may cause deactivation. In addition, alkaline conditions are required to increase the reaction rate and to avoid deactivation by reaction intermediates. Although beneficial for the reaction rate, the use of base conditions affects negatively the economics of the process as gluconate salt instead of pure gluconic acid is obtained at the end of reaction. Often, a decrease of selectivity due to the favored glucose to fructose isomerization reaction at high $\mathrm{pH}$ is observed $[6,14]$. Considering that the catalysts operate continuously under oxygen rich atmospheres Pt and Pd based catalyst could suffer also deactivation by "over-oxidation" responsible for active sites lost by oxidation. The majority of these inconvenients could be resolved by using gold based catalysts instead of platinum and palladium based ones. High selectivity and activity were reported for supported gold catalysts and convert them in the most promising candidates for future industrial implantation [8, 15-19]. Gold catalysts successfully operate under oxygen. The inert nature of the metal avoids loss of activity by oxidation and present an important activity for aldehyde group oxidation and inertness towards secondary alcoholic group oxidation [6]. Probably the most important findings concerning gold based systems is that they could operate under a wide range of $\mathrm{pH}$ with the same activity, which allows avoiding the glucose to fructose isomerization under base conditions.

Recently, the great potential of gold catalysts for direct glucose oxidation in base free conditions was demonstrated [20-23]. It was confirmed that catalyst productivity is barely influenced by the $\mathrm{pH}$ of the reaction and that the proper choice of support is very important for catalyst performance. Mineral oxides, as pure ceria or mixed cerium oxides, are not suitable as supports, since the catalysts suffer slow deactivation by metal leaching $[21,23]$. On the other hand, basic supports are reported to be most suitable in acidic conditions [20], although their stability towards hydroxylation has to be improved. 
Pointing industrial application, the catalysts should withstand continuous operation and repeated recycling for a long time, which implies low deactivation rate and/or easy activity recovery. Carbon based catalysts present excellent stability in acidic media and low active metal leaching which converts them in potential candidates to study their operation under base free glucose oxidation reaction.

In this context, the aim of this work is to study the catalytic performance of a series of $\mathrm{Au} / \mathrm{C}$ catalysts prepared by gold colloids immobilization and their recyclability under repeated operation. All possible deactivation causes as gold leaching, sintering and chemical poisoning (active sites blocking by reaction intermediates) are contemplated and related to the variation of the initial gold particle size. The viability of some catalyst' treatments between the operation cycles aiming to recover the initial deactivation was also investigated.

\section{Experimental}

\section{Catalyst preparation}

Gold was deposited from pre-formed colloids prepared by reducing of the PVA stabilized gold precursor with $\mathrm{NaBH}_{4} \cdot 5.10^{-4} \mathrm{M}$ aqueous solution of $\mathrm{HAuCl}_{4}(2 \mathrm{wt} \%$ nominal value) was mixed with the corresponding quantity of PVA ( $1 \mathrm{wt} . \%$ aqueous solution) and stirred for 20 min. After, appropriate amount of $0.1 \mathrm{M}$ freshly prepared $\mathrm{NaBH}_{4}$ solution was quickly added for other 20 min and the solution was put in contact with commercially available activated carbon powder DARCO® (Sigma Aldrich, 100 mesh particle size). After aging, the final mixture was centrifuged at $15000 \mathrm{rpm}$ for 20 minutes and resulted solids separated by filtration. Samples were finally calcined in static air at $300{ }^{\circ} \mathrm{C}$ for 2 hours. 
Following this procedure, four samples were prepared keeping constant PVA:Au weight ratio of 0.85 and varying the $\mathrm{NaBH}_{4}$ :Au molar ratio from 3 to 10 . The later was chosen in order to get different final gold particle size, as reported in previous studies [24]. Table 1 summarizes the synthesis parameters and labelling of the catalysts.

Table 1. Synthesis parameters of the prepared samples.

\begin{tabular}{|c|c|}
\hline Sample & $\begin{array}{c}\mathrm{NaBH}_{4}: \mathrm{Au} \\
\text { molar ratio }\end{array}$ \\
\hline AuC_I & 3 \\
\hline AuC_II & 5 \\
\hline AuC_III & 10 \\
\hline
\end{tabular}

\section{Characterization}

The gold contents were estimated through ICP analysis by using Horiba Jobin Yvon spectrometer.

Transmission electron microscopy (TEM) study on particle size and dispersion of the catalysts was performed on PHILIPS CM-200. The average gold particle size was estimated based on surface distribution calculations as shown in equation 1

$$
\mathrm{D}[3,2]=\frac{\sum_{1}^{\mathrm{n}} \mathrm{D}_{i}^{3} v_{i}}{\sum_{1}^{\mathrm{n}} \mathrm{D}_{i}^{2} v_{i}} \quad \text { eq. } 1
$$

where $\mathrm{D}_{\mathrm{i}}$ is the geometric diameter of the $i^{\text {th }}$ particle, and $v_{i}$ the number of particles with this diameter. For particle size distribution, the total number of measured particles overcomes 200 for every sample.

The DRIFTS spectra were recorded at room temperature without sample dilution using a Thermo Nicolet Nexus FT-IR spectrometer equipped with a liquid nitrogen cooled MCT 
detector at $4 \mathrm{~cm}^{-1}$ resolution and average of 128 scans. The whole optical path was purged with $\mathrm{CO}_{2}$ - and $\mathrm{H}_{2} \mathrm{O}$-free nitrogen. About $50 \mathrm{mg}$ of fresh or used catalyst finely grounded was loaded in the Praying Mantis ${ }^{\mathrm{TM}}$ cell for each measurement.

XPS measurements were carried out on Leybold-Hereus LHS-1020 instrument coupled with EA200 detector and using non chromatic Mg Ka (220W, 11kV, 1253,6 eV). Prior to use the sample were pressed into a thin disk. The XPS spectra of all sample were recorded at room temperature and the binding energy was calibrated on $\mathrm{C} 1 \mathrm{~s}$ at $284,6 \mathrm{eV}$ with an uncertainty $\pm 0.2 \mathrm{eV}$. The spectra were recorded with constant pass energy of 44 $\mathrm{eV}$ and $0.1 \mathrm{eV}$ resolution for the studied zones.

\section{Base free aerobic oxidation of glucose}

The oxidation of glucose was performed in a glass batch reactor $(50 \mathrm{~mL})$ at constant temperature and stirring rate at saturated oxygen atmosphere (approximate $\mathrm{P}_{\mathrm{O} 2}$ of 0.1 $\mathrm{MPa}$ ). In a typical experiment, the reactor was charged with $0.2 \mathrm{M}$ glucose aqueous solution, catalyst in Glucose/Au molar ratio of 100 and oxygen saturated by bubbling 20 $\mathrm{mL} / \mathrm{min}$ of pure oxygen flow for few minutes. The reactor was then closed and reaction mixture stirred at $600 \mathrm{rpm}$, at $40^{\circ} \mathrm{C}$ during 18 hours in base-free conditions.

The recycling study was carried out in a similar manner separating the catalyst from the products by filtration between the runs and re-using it maintaining Glucose/Au molar ratio of 100 at every run. In some cases reactivation treatments were performed. The samples after filtration were treated either with distilled water, $0.1 \mathrm{M} \mathrm{NaOH}$ solution or thermally treated at $300^{\circ} \mathrm{C}$ for $2 \mathrm{~h}$ before every run. 
The reaction products were identified and quantified by HPLC equipped with refractive index detector (Varian 360-LC) and Hi-Plex H column $(300 \times 7,7 \mathrm{~mm})$ set to $40^{\circ} \mathrm{C}$ using MilliQ water as mobile phase.

Glucose conversion and product selectivity to gluconic acid (GA) were calculated as described by equation (1) and (2).

$$
\begin{aligned}
& \text { Conversion }(\%)=\frac{[\text { Glucose }]_{\text {in }}-[\text { Glucose }]_{\text {out }}}{[\text { Glucose }]_{\text {in }}} * 100 \\
& \text { Selectivity } G A(\%)=\frac{\text { mole GA }}{\text { total moles of products }} * 100
\end{aligned}
$$

\section{Results and discussion}

The real gold loading measured by ICP and the mean particle size deduced from TEM is presented in Table 2.

Table 2. Gold metal loadings and particle size for fresh and spent catalysts.

\begin{tabular}{|c|c|c|c|c|c|}
\hline Sample & $\begin{array}{c}\text { Au wt.\% } \\
\text { (fresh), }\end{array}$ & $\begin{array}{c}\text { Au, wt.\% } \\
\text { (spent 4 } 4^{\text {th }} \text { cycle) }\end{array}$ & $\begin{array}{c}\text { Au particle } \\
\text { size, nm } \\
\text { (fresh) }\end{array}$ & $\begin{array}{c}\text { Au particle } \\
\text { size, nm } \\
\text { (spent } 1^{\text {st }} \text { cycle) }\end{array}$ & $\begin{array}{c}\text { Au particle } \\
\text { size, nm } \\
\text { (spent } 4^{\text {th }} \text { cycle) }\end{array}$ \\
\hline AuC_I & 2.2 & 1.9 & 16.1 & n.m. & 20.4 \\
\hline AuC_II & 2.4 & 1.9 & 8 & 17 & 16.6 \\
\hline AuC_III & 2.3 & 1.9 & 4.8 & 8.9 & 7.7 \\
\hline
\end{tabular}

n.m. not measured

All fresh samples present similar gold loadings close to the targeted value. The average gold particle size varies within the series attributed to the modification of the synthesis parameters, chosen in a way to have a real disparity of the initial particle size. Higher the $\mathrm{NaBH}_{4}: \mathrm{Au}$ ratio at a constant PVA:Au ratio, lower the average gold particles size. The 
synthesis parameters influence strongly the average particle size but not the actual metal loadings. The representative micrographs of AuC_II sample and its particle size distribution are presented in Figure 1.

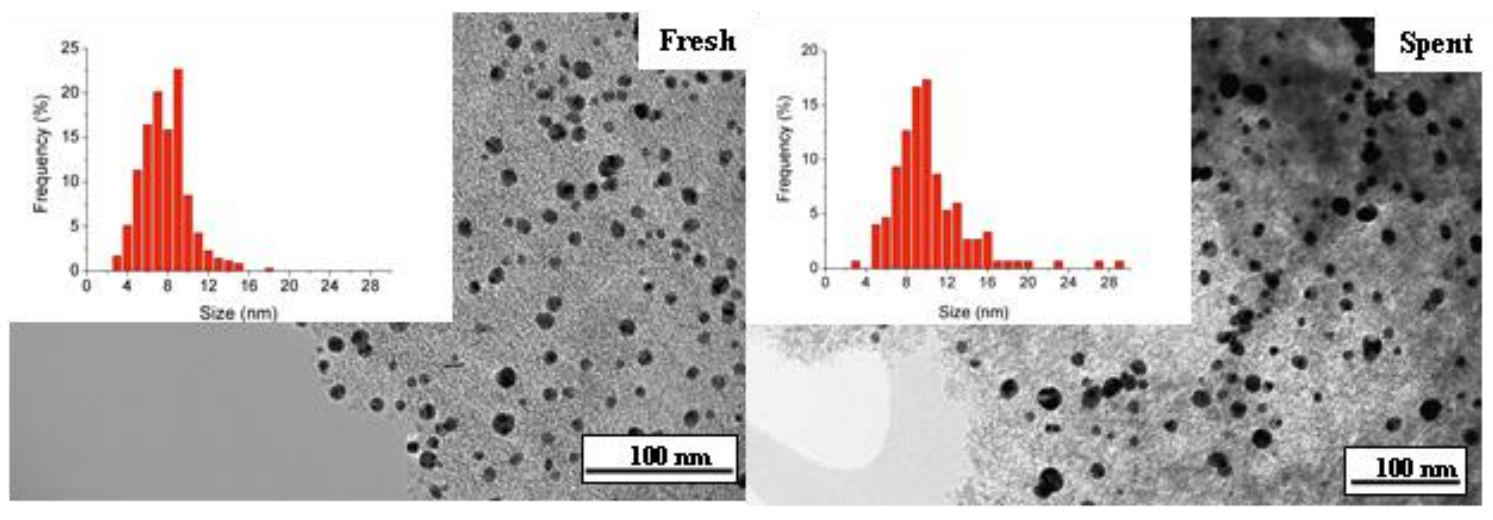

Figure 1. Representative TEM micrographs and gold size distributions for fresh and spent $\left(4^{\text {th }}\right.$ cycle) AuC_II samples.

\section{Catalytic activity and recycling study}

The catalyst activity of all samples and in every cycle, expressed as glucose conversion, is shown in Figure 2a. The calculated carbon balance ranges from 86 to $95 \%$ (first vs. last cycle) indicating possible adsorption of reactive or intermediates after the first cycle but not after all successive ones. The gluconic acid selectivity on the base of liquid nonadsorbed products was found $100 \%$ and will not be discussed from now on.

No matter the gold particles size similar glucose conversions are obtained in the first cycles neighboring $80 \%$. Systematically the second cycle gives always less conversion than the first one being the difference in the range of 20-25\%. The performed blank test with activated carbon shows that at this temperature only $8 \%$ of glucose could be adsorbed on the carbon surface and false the initially calculated glucose conversion. Anyway the deactivation of the catalyst between the $1^{\text {st }}$ and the $2^{\text {nd }}$ cycle occurs 
unequivocally. It is also observed very similar $2^{\text {nd }}$ and $3^{\text {rd }}$ cycles and slightly different $4^{\text {th }}$ cycle. The sample AuC_III shows continuous decrease of glucose conversion, while the AuC_I and AuC_II stabilized after the initial loss of activity. Nevertheless, from statistical point of view, within the series of samples only AuC_II behave differently (Figure 2a).

(a)

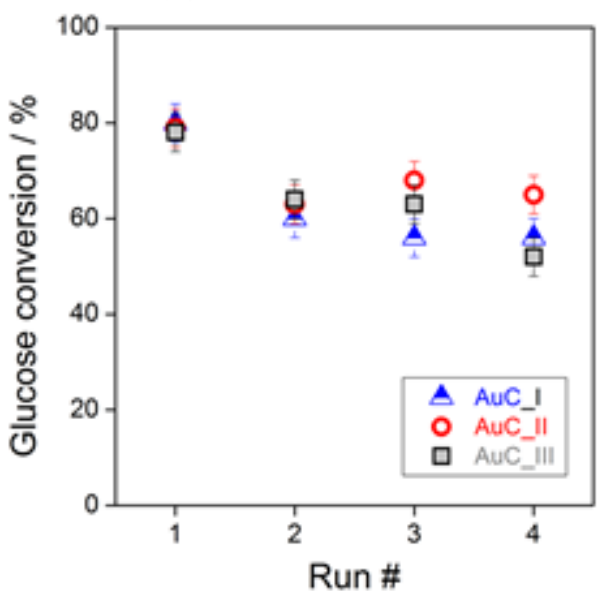

(b)

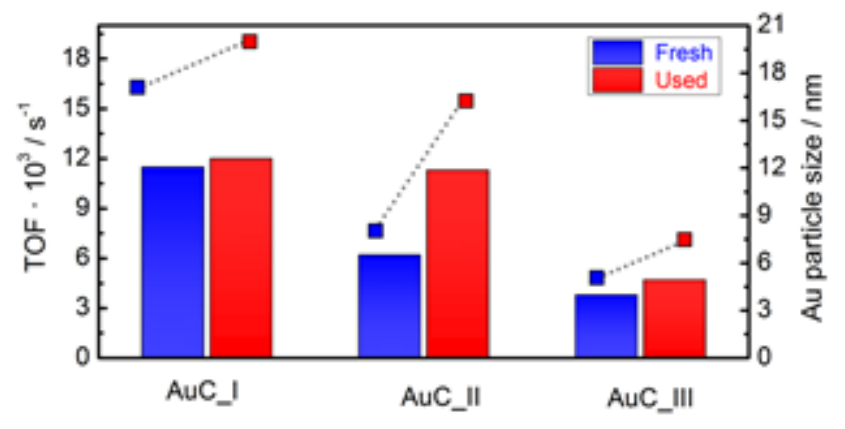

Figure 2. a) Glucose conversion on fresh and spent catalysts under 4 reaction cycles b) TOF (bars) and particle size (points) comparison in $1^{\text {st }}$ and $4^{\text {th }}$ cycles on fresh and spent catalysts.

As reported above the reasons for deactivation could be assembled in two groups, those altering directly the active sites, as sintering or metal loss, and those responsible for catalyst' blocking or support modifications. The leaching of gold was checked by ICP analysis of the remaining gold on catalyst after accomplished recycling study (Table 2) and in the filtration water before every cycle. No matter the starting catalyst and/or particle size, the same gold loss is detected averaging $15 \%$ of the initial gold loading and always the gold loss between the $1^{\text {st }}$ and the $2^{\text {nd }}$ cycle represents almost $80 \%$ of the total leaching. 
On the other hand, gold particle size is also influenced (Table 2). The sample AuC_I does not change practically its initial particle size, only a slight increase is observed. AuC_II and $\mathrm{AuC} \_$III practically doubles their size after the $1^{\text {st }}$ run after which the size remain constant in the last two runs. The increase of the average particle size is caused by the identification of some agglomerates that reflect on wider particles distribution, as presented in Figure $1 \mathrm{~b}$ for AuC_II as representative sample. The specific activity could be then recalculated for the $1^{\text {st }}$ and $4^{\text {th }}$ cycle for all catalysts, considering gold quantity and dispersion. The dispersion was calculated using cubooctahedral particles mathematical model for the theoretically available gold surface atoms and this model was compared with the experimentally observed particle size by TEM. The estimations of the gold dispersion and specific activity in the $1^{\text {st }}$ and the $4^{\text {th }}$ cycle are presented in Table 3.

Table 3. Gold particles dispersion and TOF for the fresh and spent samples $\left(1^{\text {st }}\right.$ and $4^{\text {th }}$ cycle of operation).

\begin{tabular}{|c|c|c|c|c|}
\hline Sample & $\begin{array}{c}\text { Au dispersion } \\
\text { fresh, } \%\end{array}$ & $\begin{array}{c}\text { Au dispersion } \\
\text { spent, } \%\end{array}$ & $\begin{array}{c}\text { TOF* }^{*} 0^{3} \\
\text { (fresh), } \mathrm{s}^{-1}\end{array}$ & $\begin{array}{c}\text { TOF*10 }^{3} \\
\text { (spent } 4^{\text {th }} \text { cycle), } \\
\mathrm{s}^{-1}\end{array}$ \\
\hline AuC_I & 9 & 7 & 11.5 & 12.0 \\
\hline AuC_II & 16 & 9 & 6.2 & 11.3 \\
\hline AuC_III & 27 & 18 & 3.8 & 4.7 \\
\hline
\end{tabular}

It is clear that the gold particle size increase during the $1^{\text {st }}$ cycle of operation resulting in lower dispersion almost for all samples. Although negative influence on glucose oxidation activity for a samples with gold particle size superior to $10 \mathrm{~nm}$ is reported [8, 25] the specific activity in our case shows a maximum placed between 15-20 nm average 
gold particle size (Figure 2b). As long as the gold particles neighbor the optimum average size maximum specific activity could be achieved. Prati et al. [26] found $7 \mathrm{~nm}$ as optimal gold nanoparticle size for uncalcined catalyst, slightly inferior to the size of our best fresh catalyst. This result shows that the observed decrease of glucose conversion does not reflect in decrease of specific activity indicating that the particles sintering is not of primordial importance as activity inhibitor as the gold loading is for this reaction. But the gold metal particles size must be controlled in a range appropriate for the reaction. Wang et al. [21] found that gold particle size alteration and leaching is more pronounced in acidic conditions and that a reasonable stability and activity could be achieved by proper choice of support. However, the use of mineral supports as $\mathrm{Al}_{2} \mathrm{O}_{3}$ or $\mathrm{CeO}_{2}$ based materials [23] results in even more severe gold leaching converting the carbon based supports in the most appropriate materials for this reaction conditions. The solution of the leaching problem still have to be found either by appropriate changes in the support (porosity and/or surface composition modifications) or by establishing an appropriate gold loading for high specific activity combined with low leaching rate.

Outward gold metal state (loadings and size) possible active sites blocking during the reaction was also reported as a reason for deactivation [21,27]. The surface properties of our fresh and spent catalysts were studied by XPS and DRIFT analysis. At this point as representative sample the AuC_II was selected owed to the highest changes in specific activity observed for this sample between the cycles (Figure 2 B).

The XPS spectra of fresh and spent (after $4^{\text {th }}$ cycle) AuC_II sample are presented in Figure 3.

The $\mathrm{C} 1 s$ spectra of the fresh sample can be resolved into three peaks; one corresponding to graphitic carbon $\mathrm{C}-\mathrm{C} \mathrm{sp}{ }^{2}$ bond located at $284.5 \mathrm{eV}$, one of $\mathrm{C}-\mathrm{O}$ single bond of phenols 
and esters at $285.8 \mathrm{eV}$ and the $\mathrm{C}=\mathrm{O}$ double bounded oxygen in ketones and quinones contribution at $287.0 \mathrm{eV}$. The three types of carbon are presented in the original activated carbon sample. After the $4^{\text {th }}$ cycle the observed carbon contributions could be assigned to the same groups, with the major difference observed on the second group. The relative contribution of the organic carbon issued from phenols and esters increases together with the $\mathrm{O} / \mathrm{C}$ ratio ( 0.045 vs. 0.13 for fresh and spent sample respectively). This increase could be related either to the oxidation of the activated carbon surface or to the adsorption of the reaction products. The $\mathrm{O} 1 s$ of the fresh sample indicates the presence of only one type of oxygen - "organic oxygen" $\mathrm{C}-\mathrm{O}$ at $532.6 \mathrm{eV}$ found in phenols or esters and this contribution increases dramatically after catalyst recycling. Zope and Davis [27] reported as a possible cause for gold deactivation, low catalyst' tolerance to strongly adsorbed ketones, enones or compounds with $\beta$-dicarbonyl structure issued from highly oxygenated biomass derivatives with $\mathrm{OH}$ groups bounded to the secondary $\mathrm{C}$ atoms. Those intermediate species intereact eventually and adsorb strongly on the catalyst surface, producing active sites blocking. However, no oxygen contributions assigned to the $\mathrm{C}=\mathrm{O}$ groups were observed in our XPS spectra indicating at this step, the absence of ketones on the surface and only richer in oxygen activated carbon surface at the end of the reaction.

On the other hand, the gold surface distribution, in both beginning and end of the reaction, shows the presence of metallic gold confirmed by the corresponding $4 f_{5 / 2}$ and $4 f_{7 / 2}$ transitions situated at 87.8 and $84.0 \mathrm{eV}$, respectively. The $\mathrm{Au} / \mathrm{C}$ and $\mathrm{Au} / \mathrm{O}$ atomic surface ratio decreases from fresh to spent catalyst (0.016 to 0.009 and 0.35 to 0.07 ) indicating in the first case gold particles size agglomeration (confirmed by TEM) and in the second one that the oxygen surface distribution originates more probably from intermediates and not from oxidized gold metal centers. 

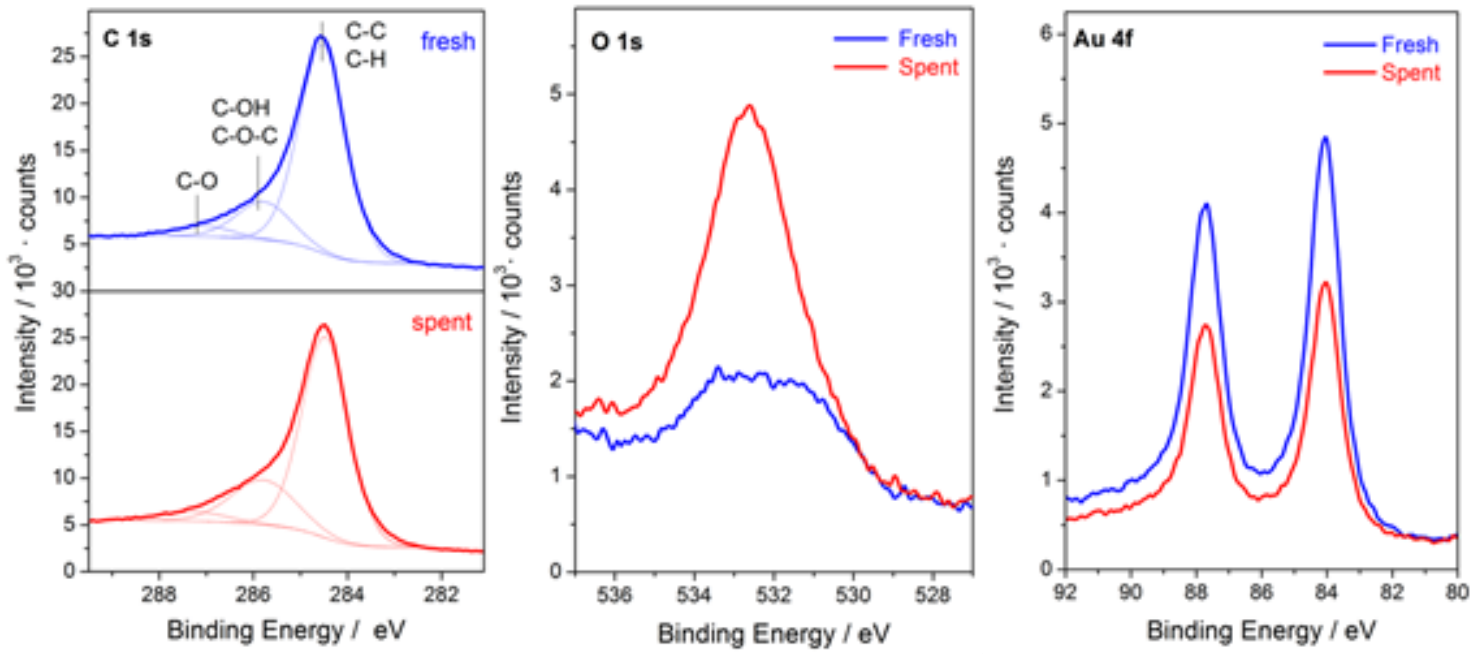

Figure 3. XPS spectra of fresh $\left(1^{\text {st }}\right.$ cycle $)$ and spent $\left(4^{\text {th }}\right.$ cycle $)$ AuC_II catalyst.

In order to estimate the role of the intermediates poisoning on the reaction and possible catalysts regeneration, different treatments $\left(\mathrm{H}_{2} \mathrm{O}, 0.1 \mathrm{M} \mathrm{NaOH}\right.$, calcination in static air at $300^{\circ} \mathrm{C}$ or no treatment) were carried out over representative sample, AuC_II. The results expressed in glucose conversion are presented in Figure 4.

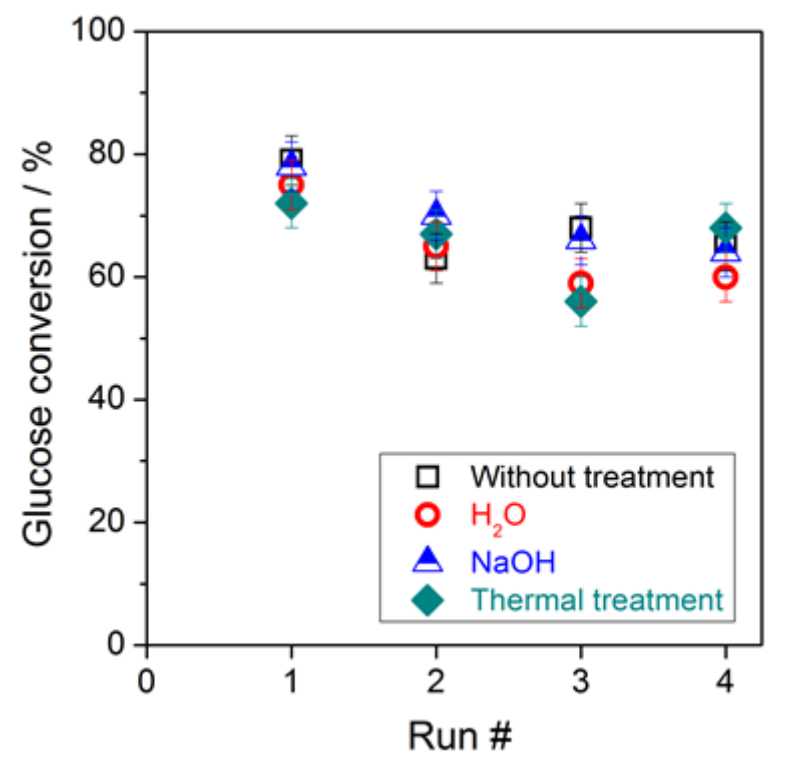

Figure 4. Activity of the AuC_II sample after various regeneration treatments.

The analysis of the results leads to the conclusion that the treatments between the cycles do not influence excessively the catalyst performance. With or without treatments, the $2^{\text {nd }}$ cycle is always affected negatively and no recuperation of initial activity is observed. 
Figure 5 present the DRIFT spectra recorded to estimate the changes induced on the catalyst surface during the first cycle of operation and during the regeneration treatments. In order to clearly discern all formed or adsorbed species, the difference DRIFT spectra taking as a reference the fresh sample are considered.

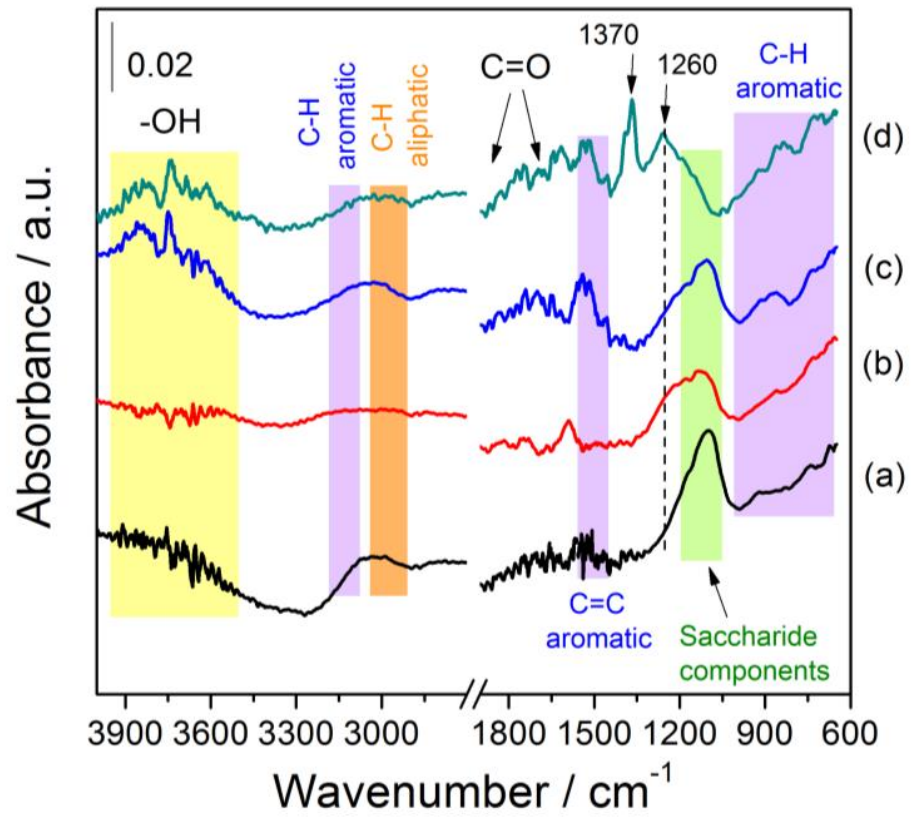

Figure 5. Difference DRIFT spectra (spent vs. fresh) under different regeneration treatments: (a) without treament, (b) $\mathrm{H}_{2} \mathrm{O}$, (c) $\mathrm{NaOH}$ and (d) thermal treatment.

As can be observed, the DRIFT spectra of the spent untreated catalysts clearly show the presence of adsorbed species or modification of the carbon support resulting after glucose oxidation. According to the literature data, all spectral features in the $900-650 \mathrm{~cm}^{-1}$ region could be attributed to the $\mathrm{C}-\mathrm{H}$ out of the plane aromatic compounds vibrations, the bands in the $3100-3000 \mathrm{~cm}^{-1}$ region to the $\mathrm{C}-\mathrm{H}$ ring stretching vibration, the bands in the 3000 $2800 \mathrm{~cm}^{-1}$ region to the $\mathrm{C}-\mathrm{H}$ aliphatic species stretching vibration and the bands in the $1600-1450 \mathrm{~cm}^{-1}$ region to the ring carbon-carbon stretching vibration, all caused by the presence of activated carbon [28,29]. In addition, the broad band with several contributions observed in the $1150-1050 \mathrm{~cm}^{-1}$ region could be assigned to the presence of 
polysaccharide (highly oxygenated) compounds [30]. Also bands in the $1600-1850 \mathrm{~cm}^{-1}$ range are observed and attributed to the $\mathrm{C}=\mathrm{O}$ stretching vibration of carbonyl groups in aldehydes, ketones, carboxylic acids, esters or acid anhydrides [31-33]. Both regions (1150-1050 $\mathrm{cm}^{-1}$ and $\left.1600-1850 \mathrm{~cm}^{-1}\right)$ indicate the presence of intermediates and/or products adsorbed on the catalyst surface. Also pronounced broad band in the 3900-3500 $\mathrm{cm}^{-1}$ indicates the presence of hydrogen bonds involved $-\mathrm{OH}$ groups. The assignment in this region, however, is of complex nature, since it includes contributions from various groups.

After regeneration, the samples treated with water and $\mathrm{NaOH}$ present similar bands to the untreated spent catalyst. Only a slight modification in the $-\mathrm{OH}$ stretching region seems to occur upon $\mathrm{NaOH}$ treatment. The saccharide like compounds remain adsorbed on the surface upon water and $\mathrm{NaOH}$ treatment. By contrast, the thermal treatment lead to polysaccharide bands disappearance and the appearance of two new bands. The first broad band centered at $1260 \mathrm{~cm}^{-1}$ could be assigned to the $\mathrm{C}-\mathrm{O}$ stretching modes typical for ester/ ether bridging groups, phenols and lactones [29] and the second at $1370 \mathrm{~cm}^{-1}$ to $\delta$ $\mathrm{O}-\mathrm{H}$ vibrations and $v \mathrm{C}=\mathrm{O}$ vibrations [34]. The thermal treatment transformed the adsorbed polysaccharide species into new oxygen-containing compounds. Those compounds could result either from the subsequent oxidation of the initially adsorbed species or from the modification of the support and from its oxidation during the calcination treatment in static air. Therefore, it could be concluded that the adsorbed species during the reaction, strongly adsorbed on the catalyst surface, could not be removed without thermal treatment. Nevertheless nor soft chemical treatments $\left(\mathrm{H}_{2} \mathrm{O}\right.$ and $\mathrm{NaOH}$ ) nor harder calcination treatment can regenerate the initial state of the catalyst. The adsorbed and remaining species on the surface formed after the $1^{\text {st }}$ run $\left(\mathrm{H}_{2} \mathrm{O}, \mathrm{NaOH}\right.$ or thermal treatments) do not change the catalyst activity ( $\operatorname{similar} 2^{\text {nd }}, 3^{\text {rd }}$ and $4^{\text {th }}$ cycle) 
indicating that nor the adsorbed intermediates nor the modification of the support play important role in catalyst deactivation. The similar $2^{\text {nd }}, 3^{\text {rd }}$ and $4^{\text {th }}$ cycles demonstrate also that the presence of adsorbed intermediates or modifications of the support does not inhibit the reaction. It seems that gold metal state, i.e. gold particle size variation and metal leaching, is the most important parameter inducing loss of activity. On one hand the particles agglomeration could result in a beneficial optimal particle size and increase in the specific activity (AuC_II). And on the other, in our previous study [23] it was reported that the leached gold could participate in the reaction with around $10 \%$ conversion increase between the $4^{\text {th }}$ and the $18^{\text {th }}$ hour of reaction which together with the $8 \%$ of glucose adsorption on activated carbon accounts for the $20 \%$ of glucose conversion decrease between the $1^{\text {st }}$ and the $2^{\text {nd }}$ cycle. All this leads to the conclusion that the most important problem to solve is gold metal leaching.

This statement leads to the assumption that the carbon support is not a key parameter in this reaction and that the glucose oxidation is occurring only on the low defect surface gold particles with preferable average size of $15-20 \mathrm{~nm}$. Ishida et al. [8] also suggested that the glucose oxidation reaction occurs preferably on gold particles surface and not on the gold/support interface or support. Our observations also support this idea, as the most important deactivation is produced by the gold state change.

The mechanism of glucose oxidation in alkaline conditions is already known and includes preferable glucose adsorption on hydroxylated Au surface on which the glucose $\mathrm{CHO}$ group is firstly activated. After water is released by formyl group $\mathrm{H}$ removal and gluconic acid is formed by $\mathrm{OH}$ transfer from the Au surface [35]. However, in base free conditions the glucose oxidation should proceed through carbonyl conjugated radical [36] and probably will include oxidation through hydrogen peroxide formation, as the activation of molecular oxygen is improbable on gold. Comotti et al. [37] proposed as a key reaction 
step the presence of electron-rich gold species, formed by hydrated glucose anions on gold surface atoms, which activate the molecular oxygen by nucleophilic attack and lead to the formation of hydroxyperoxides, represented schematically in Figure 6.

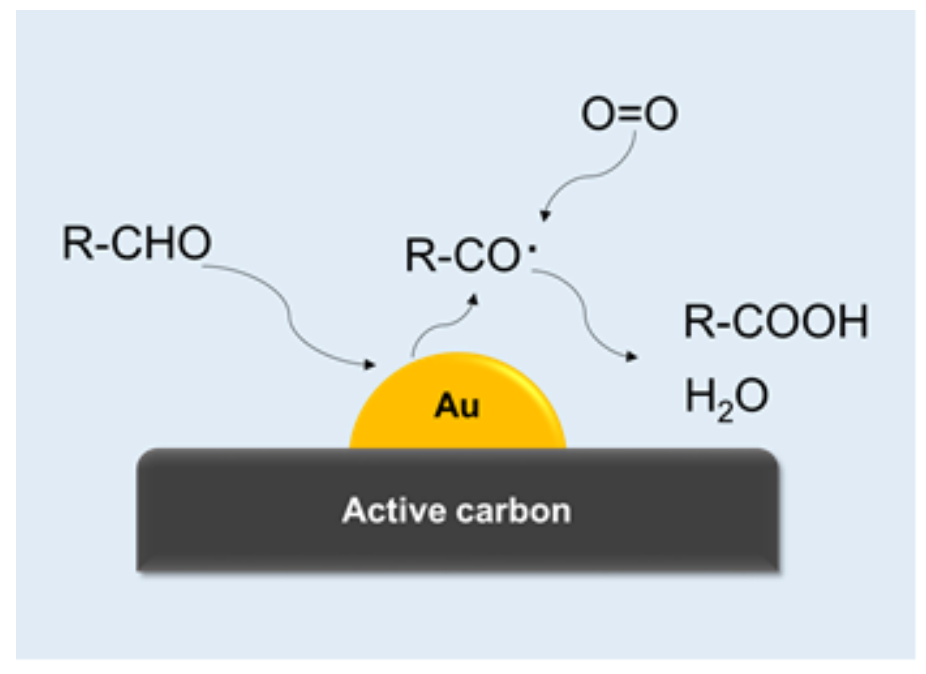

Figure 6. Representation of possible mechanism of glucose oxidation in base free conditions.

This step could be considered as one of the of Baeyer-Villiger reaction steps, including addition of peroxide to formyl group with hydroxyperoxide formation and its rearranging with cleavage of the $\mathrm{C}-\mathrm{C}$ bond and products formation [38]. The proposed reaction steps are only a tentative for predicting the reaction mechanism in base free conditions. However a detailed study is needed to confirm the viability of the proposed reaction pathway.

\section{Conclusions}

Several sample with varying gold particle size are prepared and tested in base free oxidation of glucose. The samples show similar behavior around $80 \%$ of glucose conversion toward $100 \%$ selective gluconic acid production in the first cycle of reaction. The recycling of the samples reveals that deactivation occurs after the $1^{\text {st }}$ cycle independently on the initial gold particle size. Gold leaching is confirmed to be the 
primary reasons for catalyst deactivation. Also a gold agglomeration occurs and results beneficial for the specific activity improvement when optimal gold average size is achieved. On the other hand, the support nature, its chemical state or adsorbed species do not seem to be very important. All reactivation treatments result in the same activity trend indicating that the catalyst operation is not affected by intermediates adsorption, removal or support modification. Therefore, every loss of activity is due to gold metal leaching after the $1^{\text {st }}$ cycle and when the leaching stops the activity remains constant $\left(2^{\text {nd }}, 3^{\text {rd }}, 4^{\text {th }}\right.$ cycle).

\section{Acknowledgements}

Financial support for this work has been obtained from the Spanish Ministerio de Economía y Competitividad (MINECO) (ENE2013-47880-C3-2-R) co-financed by FEDER funds from the European Union. 


\section{References}

[1]. C. Chatterjee, F. Pong, A. Sen, Green Chem., 2015, 17, 40-71.

[2]. J. C. Serrano-Ruiz, R. Luque, A. Sepúlveda-Escribano, Chem. Soc. Rev., 2011, 40, $5266-5281$

[3] J. Chedda, G. W. Huber, J. A. Dumesic, Angew. Chem. Int. Ed., 2007, 46, 71647183.

[4] Frieder W. Lichtenthaler, Siegfried Peters, C. R. Chimie 7 (2004) 65-90.

[5] M. Besson, P. Callezot, Catalysis Today, 57, 2000, 127-144

[6] S. Biella, L. Prati, M. Rossi, J. Catal, 206, 2002, 242-247.

[7] P. Beltrame, M. Comotti, C. Della Pina, M. Rossi, Appl. Catal. A Gen. 297 (2006) $1-7$.

[8] T. Ishida, N. Kinoshita, H. Okatsu, T. Akita, T. Takei, M. Haruta, Angew. Chemie Int. Ed. 47 (2008) 9265-9268.

[9] M. J. Climent, A. Corma, S. Iborra, Green Chem., 13, 2011, 520-540.

[10] D. J. Verraest, J. A. Peters, H. van Bekkum, Carbohydr. Res. 306 (1998) 197-203

[11] J.M.H. Dirkx, H.S. van Der Baan, J. Catal. 67 (1981) 1-13.

[12] M. Besson, F. Lahmer, P. Gallezot, P. Fuertes, G. Fléche, J. Catal. 152 (1995) 116121.

[13] P. Gallezot, Catal. Today. 37 (1997) 405-418. 
[14] C. Kooyman, K. Vellenga, H.G.J.D.E. Wilt, Carbohydrate Research, 54 (1977) 3344.

[15] C. Baatz, U. Prüße, J. Catal. 249 (2007) 34-40.

[16] N. Thielecke, K. D. Vorlop, U. Prüße, Catal. Today 122 (2007) 266-269.

[17] U. Prüße, M. Herrmann, C. Baatz, N. Decker, Appl. Catal. A, 406 (2011) 89-93.

[18] A. Mirescu, H. Berndt, A. Martin, U. Prüße, Appl. Catal. A, 317 (2007) 204-209.

[19] C. Baatz, N. Thielecke, U. Prüße, Appl. Catal. B, 70 (2007) 653-660.

[20] P. J. Miedziak, H. Alshammari, S. A. Kondrat, T. J. Clarke, T. E. Davies, M. Morad, D. J. Morgan, D. J. Willock, D. W. Knight, S. H. Taylora, G. J. Hutchings, Green Chem., 2014, 16, 3132-3141.

[21] Y. Wang, S. Van de Vyver, K. K. Sharma, Y. Román-Leshkov, Green Chem., 2014, 16, 719-726.

[22] P. Qi, S. Chen, J. Chen, J. Zheng, X. Zheng, Y. Yuan, ACS Catal. 2015, 5, 2659-2670.

[23] C. Megías-Sayago, S. Ivanova, C. López-Cartes, M.A. Centeno, J.A. Odriozola, Catalysis Today 279 (2017) 148-154.

[24] J. Luoa, W. Chu, S. Sall, C. Petit, Col. Surf. A: Physicochem. Eng. Aspects 425, 2013, 83-91.

[25] H. Okatsu, N. Kinoshita, T. Akita, T. Ishida, M. Haruta, Appl. Catal. A: Gen. 369 (2009) 8-14. 
[26] L. Prati, A.Villa, A. Lupini, G. Veith, Phys. Chem. Chem. Phys.2012, 14, 29692978.

[27] B. Zope, R. Davis, Green Chem. 2011, 13, 3484-3491.

[28] B.J. Meldrum, C.H. Rochester, Fuel 70 (1991) 57-63.

[29] Brian J. Meldrum and Colin H. Rochester, J Chem Soc Faraday Trans 86 (1990) $861-865$.

[30] Sócrates, Infrarred and Raman characteristic group frequencies, 3rd edition, Wiley

[31]. J.L Figueiredo, M.F.R Pereira, M.M.A Freitas, J.J.M Órfão, Carbon 37 (1999) 1379-1389.

[32] Brian J. Meldrum and Colin H. Rochester, J Chem Soc Faraday Trans 86 (1990) $1881-1884$

[33] Abdel-Nasser A. El-Hendawy, J Anal Appl Pyrolisis 75 (2006) 159-166.

[34]. Douglas B. Mawhinney, John T. Yates Jr., Carbon 39 (2001) 1167-1173.

[35] T. Ishimoto, Y. Hamatake, H. Kazuno, T. Kishida, M. Koyama, Appl. Surface Sci. $324,2015,76-81$

[36] S: J. H. F. Arts, E. J. M. Mombang, H. van Bekkum, R. Sheldon, Synthesis 6 (1997) 597-613

[37] M.Comotti, C. Della Pina, E. Falletta, M. Rossi, Adv. Synth. Catal. 2006, 348, 313 $-316$.

[38] Hassall, C. H. 2011. The Baeyer-Villiger Oxidation of Aldehydes and Ketones. Organic Reactions. 9:3:73-106. 